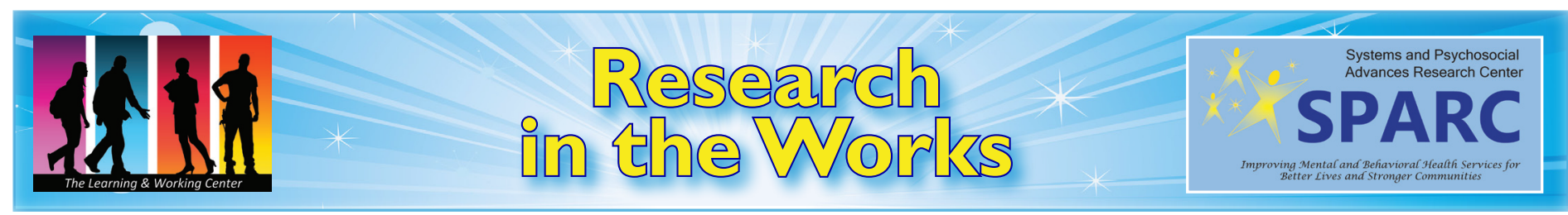

$\begin{array}{lll}\text { Vol } 14 \text { Iss } 9 & \text { A Publication of the Systems and Psychosocial Advances Research Center } \\ \text { Sept } 2017 & \text { A Massachusetts Department of Mental Health Research Center of Excellence }\end{array}$

\title{
Peer Academic Support for Success (PASS): Peer Coaching for College Students with Serious Mental Health Conditions (SMHCs)
}

Project Goal: Produce a first-of-its-kind empirically supported peer coaching intervention to help college students with serious mental health conditions (SMHCs) succeed academically at college.

\section{Background}

- Many psychiatric disorders such as depression, anxiety disorders, psychoses, and eating disorders commonly appear just before or during the years a young person would traditionally pursue a college degree (one's midteens and early twenties). ${ }^{1}$

- Only $11 \%^{2}$ of young adults with SMHCs attend 4 -year colleges, compared to $30 \%{ }^{2}$ of young adults in the general population.

- College students with SMHCs have higher dropout rates and lower graduation rates compared to college students without SMHCs. ${ }^{3-5}$

Given the advantage that a college education provides in today's labor market, it is imperative to provide strong academic supports to successfully launch the college careers of students with SMHCs.

The Peer Support for Success (PASS) coaching intervention provides a full school year of individualized academic peer coaching to freshman and sophomore college students with SMHCs. The goal of coaching is to support academic success and self-efficacy. To achieve these goals, coaching is delivered by a fellow college student (with or without SMHC), and promotes the following skills and capacities:

\footnotetext{
$\checkmark$ Effective time management

$\checkmark$ Resiliency
}

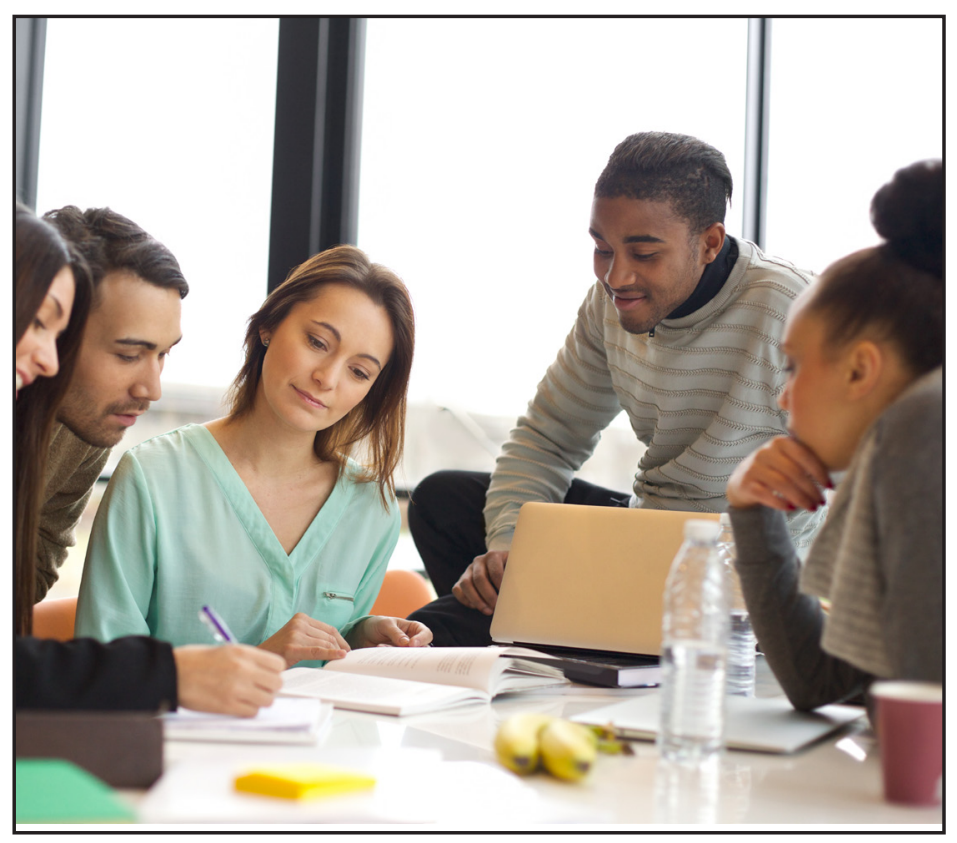

$$
\begin{array}{ll}
\checkmark & \text { Self-advocacy } \\
\checkmark & \text { Supportive tools, resources, and technology }
\end{array}
$$

\section{Project Activities}

Researchers at the Learning and Working Center within the Transitions Research \& Training Center at UMass Medical School, Wright State University (WSU), Boston University (BU) and UMass Boston (UMB) are leading the development of PASS. This research uses participatory action research methods; partnering with young adults with lived experience with SMHC and college in the design, conduct, interpretation, and dissemination of research findings. PASS is based on two pre-existing peer coaching interventions:

- Wright State University's Raiders on the Autism Spectrum Excelling (RASE) peer coaching intervention for students with autism spectrum disorders; and

- Boston University Center for Psychiatric Rehabilitation's college coaching intervention developed for students with SMHCs 


\section{Development and implementation of the PASS intervention is a 5-year project, with four distinct research phases:}

\begin{tabular}{|c|c|}
\hline Research Phase & Research Activities \\
\hline $\begin{array}{l}\text { Qualitative Interviews } \\
\text { (Phase 1) }\end{array}$ & $\begin{array}{l}\text { - Conduct qualitative interviews with } 21 \text { faculty, } 7 \text { counseling center staff, } 7 \text { disability services staff } \\
\text { and } 25 \text { college students at WSU, BU and UMB to better understand the academic experiences of } \\
\text { college students with SMHCs. }\end{array}$ \\
\hline $\begin{array}{l}\text { Specify and Develop } \\
\text { Adaptations } \\
\text { (Phase 2) }\end{array}$ & $\begin{array}{l}\text { - Develop the PASS peer coaching intervention model based on; } \\
\text { - Knowledge gained from Phase } 1 \text { qualitative interviews } \\
\text { A review of the current literature on best practices for supporting academic success of } \\
\text { collegents with SMHCs } \\
\text { Modifications to RASE and BU coaching interventions to address barriers to academic } \\
\text { achievement in college students with SMHCs. }\end{array}$ \\
\hline $\begin{array}{l}\text { Pilot Open Trial } \\
\text { (Phase 3) }\end{array}$ & $\begin{array}{l}\text { - Implement the PASS intervention on the BU campus for } 10 \text { college students with SMHCs. } \\
\text { - Revise intervention and research protocols based on open trial findings. }\end{array}$ \\
\hline $\begin{array}{l}\text { Pilot Randomized } \\
\text { Controlled Trial } \\
\text { (Phase 4) }\end{array}$ & $\begin{array}{l}\text { - Conduct a pilot randomized control trial with } 50 \mathrm{BU} \text { college students with } \mathrm{SMHCS} \text { randomly assigned } \\
\text { to receive the finalized PASS peer coaching intervention or usual supports (control condition). } \\
\text { - Identify research methods needed to conduct a large, rigorous randomized control trial of PASS in } \\
\text { the next stage of research. } \\
\text { - Disseminate findings through a variety of mechanisms such as written materials, conference } \\
\text { presentations, national webinars, a training manual, etc. }\end{array}$ \\
\hline
\end{tabular}

References
1. Patel, V., Flisher, A. J., Hetrick, S., \& McGorry, P. (2007). Mental health of young people: A global public-health challenge. The Lancet, 369(9569), 1302-1313. doi:10.1016/S0140-6736(07)60368-7

2. Wagner, M., \& Newman, L. (2012). Longitudinal transition outcomes of youth with emotional disturbances. Psychiatric Rehabilitation Journal, 35(3), 199-208. doi:10.2975/35.3.2012.199.208

3. Davis, M., \& Vander Stoep, A. (1997). The transition to adulthood for youth who have serious emotional disturbance: Developmental transition and young adult outcomes. Journal of Behavioral Health Services Research, 24(4), 400-427.

4. Kessler, R. C., Foster, C. L., Saunders, W. B., \& Stang, P. E. (1995). Social consequences of psychiatric disorders, I: Educational attainment. American Journal of Psychiatry, 152 (7), 1026-1032.

5. Salzer, M., Wick, L., \& Rogers, J. (2008). Familiarity with and use of accommodations and supports among postsecondary students with mental illnesses. Psychiatric Services, 59(4), 370-375. doi:10.1176/appi.ps.59.4.370

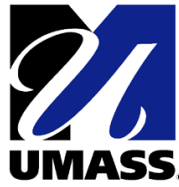

Systems snd Psychosociel
Advances Research Center
Project Personnel: Learning and Working Center within the Transitions Research \& Training Center: Maryann Davis, Ph.D. (PI), Amanda Costa, B.S. (Co-PI), Laura Golden, B.A., Kathryn Sabella, M.A.; at Boston University: Dori Hutchinson, Sc.D., Mathis Bauchner; at Wright State University: Mary Huber, Ph.D. CRC, Heather Rando, M.S.Ed., Andrew Voss, Ph.D.; at University of Massachusetts, Boston; Virginia Perelson, M.Ed.; Tracy Reed; B.A. Project Period: July 2015 - September 2019. Funder: The National Institute on Disability, Independent Living, and Rehabilitation Research (NIDILRR), and from the Center for Mental Health Services of the Substance Abuse and Mental Health Services Administration, United States Department of Health and Human Services (ACL Grant \# 90RT5031, The Learning and Working Transitions RRTC). NIDILRR is a Center within the Administration for Community Living (ACL), Department of Health and Human Services (HHS). The contents of this Research in the Works publication do not necessarily represent the policy of NIDILRR, ACL, HHS, or SAMHSA and you should not assume endorsement by the Federal Government. Contact person: Amanda.costa@umassmed.edu
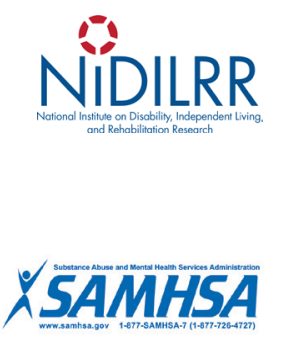

This is a product of Psychiatry Information in Brief. An electronic copy of this issue with full references can be found at http://escholarship.umassmed.edu/pib/vol14/iss9/1 